\title{
Gastrointestinal tract-like muscular walls in ovarian mature cystic teratomas: A histopathological study
}

\author{
SUSUMU MATSUKUMA ${ }^{1,2}$, OH TAKAHASHI $^{1}$, YOSHITAKA UTSUMI $^{1}, \operatorname{KOSUKE~MIYAI}^{1}$ and HIROAKI TAKEO $^{1}$ \\ ${ }^{1}$ Department of Pathology and ${ }^{2}$ Health Care Center, Japan Self-Defense Forces Central Hospital, Tokyo 154-8532, Japan
}

Received April 26, 2017; Accepted June 2, 2017

DOI: $10.3892 / \mathrm{mco} .2017 .1381$

\begin{abstract}
To elucidate the frequency and histopathological features of gastrointestinal (GI) tract-like muscular walls developing in ovarian mature cystic teratoma (MCT), the present study examined 149 MCTs surgically removed from 126 females, including 23 bilateral cases. GI tract-like muscular walls were identified in $9(7.1 \%)$ cases, and were accompanied by mucosa in 5 cases, muscularis mucosae in 5 cases, serosa in 5 cases and all of these components in 3 cases. The mean size of the GI tract-like structures was $0.6 \mathrm{~cm}$. The presence of MCT-related GI tract-like muscular walls was not significantly associated with patient age, size of MCTs or bilateral presence of MCT. The detected mucosae and muscular walls commonly demonstrated incomplete or anomalous features. Immunohistochemically, a few weakly $\mathrm{KIT}^{+}$spindle and/or stellate cells were identified in 7 cases $(77.8 \%$ of the 9 cases of MCT-related GI tracts); these cells were presented chiefly near conspicuous or inconspicuous S-100 protein ${ }^{+}$neural tissues between the conspicuous or inconspicuous two muscular wall layers, indicating interstitial cells of Cajal (ICCs). Discovered on gastrointestinal stromal tumors 1 co-expression in $\mathrm{KIT}^{+}$ICCs was observed in only 1 case. Neural cell-related intramuscular cluster of differentiation $34^{+}$cells were occasionally observed; however, no hyperplastic ICCs were observed in the present study.
\end{abstract}

\section{Introduction}

Mature cystic teratomas (MCTs) are the most common ovarian tumors, accounting for $20 \%$ of all ovarian tumors, and are composed of mature tissues derived from two to three germ

Correspondence to: Dr Susumu Matsukuma, Health Care Center, Japan Self-Defense Forces Central Hospital, 1-2-24 Ikejiri, Tokyo 154-8532, Japan

E-mail: skuma@cocoa.plala.or.jp

Abbreviations: DOG1, discovered on gastrointestinal stromal tumors 1; GI, gastrointestinal; GIST, gastrointestinal stromal tumor; $\mathrm{H} \& \mathrm{E}$, hematoxylin and eosin; ICC, interstitial cell of Cajal; K7, keratin 7; K20, keratin 20; MCT, mature cystic teratoma; MM, muscularis mucosae; SMA, $\alpha$-smooth muscle action

Key words: teratoma, GI tract, ICC, KIT, DOG1, cluster of differentiation 34 , ovary, GIST layers (ectoderm, mesoderm and endoderm) (1-4). Patients present with tumor-related symptoms, such as abdominal pain with or without tumor torsion, abdominal mass and abdominal swelling (2-4). However, a considerable amount of MCTs are asymptomatic and are incidentally discovered by pelvic examination, caesarean section or surgery for other diseases (2-4). Almost all MCTs have cystic spaces surrounded by organized skin-like tissues composed of ectoderm-derived epidermis, sebaceous glands and hair follicles and mesoderm-derived dermal stromal elements, which together contribute to the synonym 'dermoid cysts' (1-4). Other commonly found tissues include adipose tissues, smooth muscle, glia, cerebrum, peripheral nerve, cartilage, bone and respiratory epithelium (1-4). Thyroid tissues, salivary glands and ependymal tissues are occasionally present. Gastrointestinal (GI) epithelium and organized GI tracts may be observed in MCTs (5-12). To date, only two previous articles $(11,12)$ have described interstitial cells of Cajal (ICC) within the GI tract-like muscular walls in three sporadic cases of MCT. However, the frequency and histopathological features of these muscular walls are not fully understood. Therefore, the present study examined GI tract-like muscular walls in surgically removed ovarian MCTs.

\section{Patients and methods}

Patients. A total of 149 ovarian MCTs removed from 126 females were retrieved from the surgical pathology files of the Department of Pathology, Japan Self-Defense Forces Central Hospital (Tokyo, Japan), from between November 1983 and September 2016. The clinical findings and macroscopic features were obtained from surgical pathology request forms and patient medical charts. Patients ranged in age from 14-79 years (mean, 35.1 years). Of the patients, 23 had bilateral ovarian MCTs and the other 103 had unilateral MCTs. The sizes of 144 MCTs were known, and ranged from $1-21 \mathrm{~cm}$ (mean, $6.6 \mathrm{~cm}$ ). The present study was a retrospective study, which was approved by the Medical Research Ethics Committee of Japan Self-Defense Forces Central Hospital (approval number, 28-015).

MCT examination. All representative hematoxylin and eosin (H\&E)-stained sections were histologically examined for the presence of MCT-related GI tract-like muscular walls with or without other components. In the present study, the term 


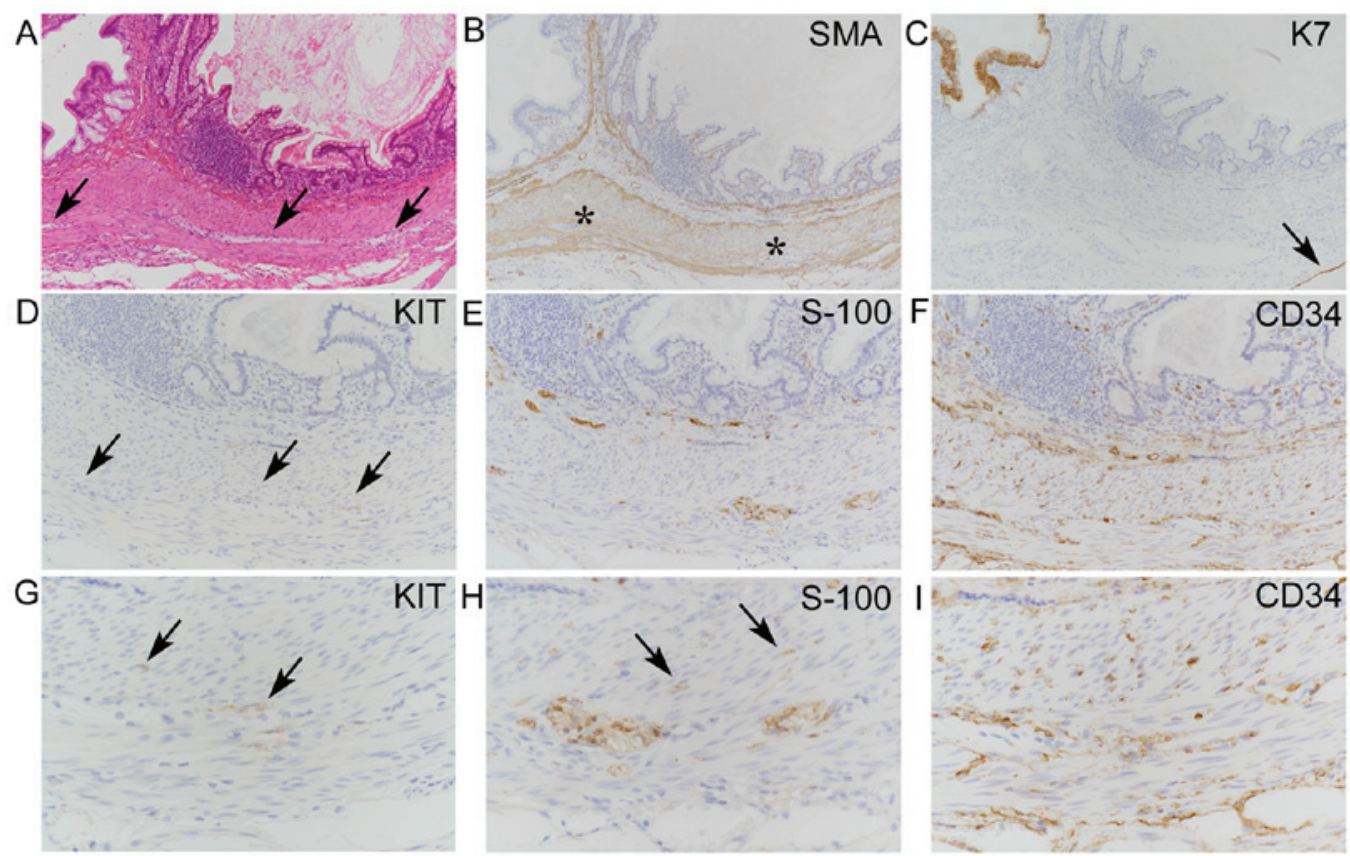

Figure 1. Histopathological analysis of gastrointestinal tract-like structures in a teratoma (case 4). (A) Hematoxylin and eosin-stained intestinal mucosa and atrophic gastric mucosa surrounded by a muscular wall with scattered neural tissues (arrows) inconspicuously observed between two muscular layers. (B) Immunohistochemical staining of SMA in the muscular wall (asterisks) revealed partially decreased expression. (C) $\mathrm{K} 7^{+}$immunostaining in gastric mucosa and serosa (arrow) (A-C magnification, x100). (D-F) Moderate-power views (magnification, x200) of immunostaining for (D) KIT (E) S-100 protein and (F) CD34. (G-I) High-power (magnification, x400) views of (D), (E) and (F), respectively. (D) A few KIT ${ }^{+}$spindle or stellate cells graded as 1, chiefly between two muscular layers (arrows), and a (G) high-power view suggesting their close proximity to S-100 protein ${ }^{+}$and CD34 ${ }^{+}$cells shown in (H) and (I), respectively. (E) S-100 protein ${ }^{+}$neural cells within the muscular layer itself, graded as 2, together with S-100 protein ${ }^{+}$distinct neural tissues, and a (H) high-power view of intramuscular S-100 protein ${ }^{+}$spindle cells (arrows). (F) Increased intramuscular CD34 ${ }^{+}$cells in the muscular wall, graded as 3, and a (I) high-power view. The distributions of intramuscular S-100 protein ${ }^{+}$cells and $\mathrm{CD} 34^{+}$cells were similar. SMA, smooth muscle actin; K7, keratin 7; CD34, cluster of differentiation 34 .

'muscular walls' was used to describe muscularis propria-like layered aggregations of smooth muscle cells, and did not include muscularis mucosae (MM). To exclude respiratory, urogenital and uterine cervical walls, muscular walls covered by ciliated columnar, squamous and/or urothelial-like epithelium were not considered.

For all samples, 10-20\% buffered formalin-fixed and paraffin-embedded representative sections containing MCT-related muscular walls were available. The fixation was performed at room temperature, ranging in duration from 12-48 h. These sections were serially cut (4-5 $\mu$ m-thick), stained with $\mathrm{H} \& \mathrm{E}$, and subjected to immunohistochemical analysis by incubation with antibodies against KIT (polyclonal; A4501; 1:100; Dako; Agilent Technologies, Inc., Santa Clara, CA, USA) for 60 min, cluster of differentiation (CD) 34 (NU-4A1; 413361; 1:100 dilution; Nichirei Biosciences, Inc., Tokyo, Japan) for 30 min, $\alpha$-smooth muscle actin (SMA; 1A4; 412021; prediluted; Nichirei Biosciences, Inc.) for $60 \mathrm{~min}, \mathrm{~S}-100$ protein (polyclonal; 422091; prediluted; Nichirei Biosciences, Inc.) for $60 \mathrm{~min}$, synaptophysin (27G12; 413831; prediluted; Nichirei Biosciences, Inc.) for $30 \mathrm{~min}$, discovered on gastrointestinal stromal tumors 1 (DOG1; K9; NCL-L-DOG-1; 1:100; Leica Biosystems, Newcastle, UK) for $60 \mathrm{~min}$, keratin 7 (K7; OV-TL 12/30; M7018; 1:100; Dako; Agilent Technologies, Inc.) for $30 \mathrm{~min}$ and keratin 20 (K20; Ks 20.8; M7019; 1:100; Dako; Agilent Technologies, Inc.) for $30 \mathrm{~min}$. For secondary antibody incubation, Histofine Simple Stain MAX PO (MULTI) ${ }^{\circledR}(424152$; Nichirei Biosciences, Inc.) was used for a duration of $30 \mathrm{~min}$. Incubations with primary and secondary antibodies were performed at room temperature. Endogenous peroxidase activity and non-specific background staining was blocked with 3\% hydrogen peroxidase and the blocking solution, Protein Block Serum-Free ${ }^{\circledR}$ (X0909; Dako; Agilent Technologies, Inc.), respectively. Each blocking reagent was incubated for $30 \mathrm{~min}$ at room temperature before incubation with the primary and secondary antibodies.

Excluding distinct neural tissues and vessels observed on $\mathrm{H} \&$ E-based histology, $\mathrm{KIT}^{+}, \mathrm{CD} 34^{+}, \mathrm{S}-100^{+}$, synaptophysin ${ }^{+}$ and $\mathrm{DOG} 1^{+}$spindle or stellate cells within muscular walls were evaluated in each case, and were graded as follows: 0 , no positive cells; $1,<1 \%$ positive muscular wall spindle and/or stellate cells; $2,1-5 \%$ positive muscular wall spindle and/or stellate cells; and 3 , cells $>5 \%$ positive muscular wall spindle and/or stellate cells.

Statistical analysis. Clinicopathological findings were analyzed using the appropriate Spearman's rank correlation test and Fisher's exact test. Data were analyzed on a personal computer using a statistical software package (StatMate ${ }^{\circledR}$ IV for Windows v. 4.01; ATMS Corp., Ltd., Tokyo, Japan). $\mathrm{P}<0.05$ was considered to indicate a statistically significant difference.

\section{Results}

Clinicopathological features. GI tract-like muscular walls were hemi-laterally identified in $9(7.1 \%)$ of 126 cases of MCT (4 left and 5 right MCTs). Table I summarizes the main clinicopathological findings in these 9 patients. These walls were 


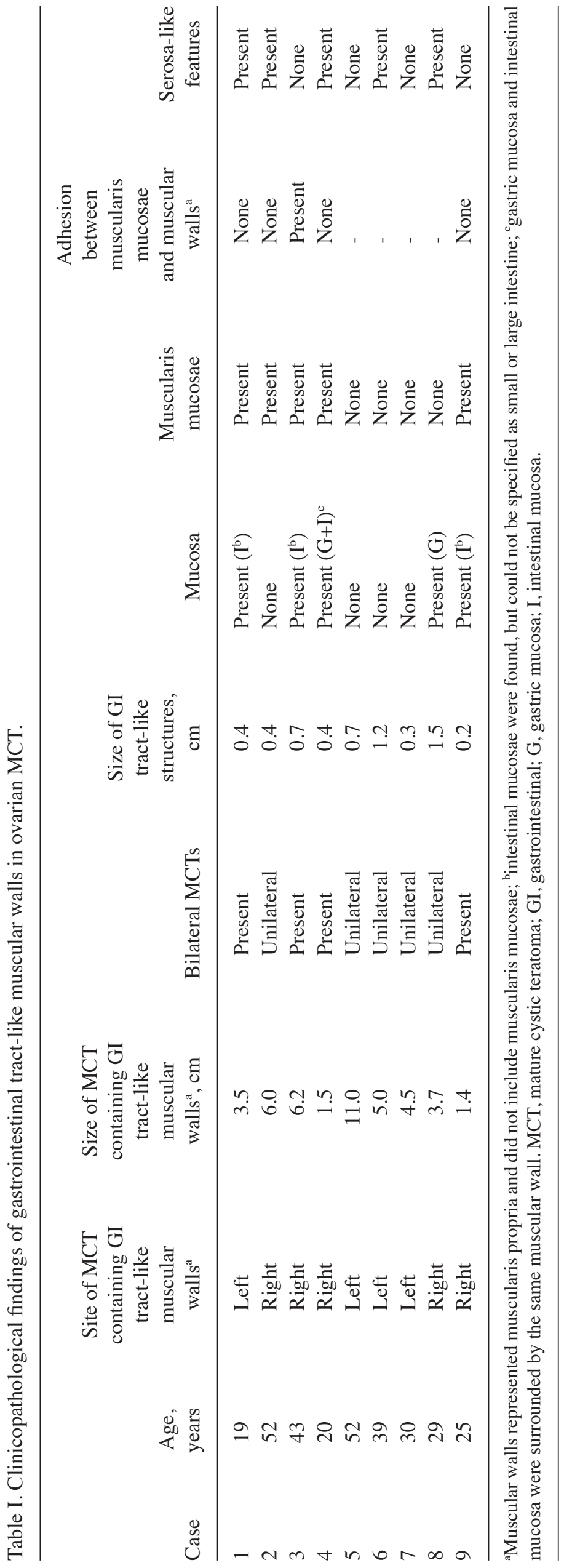



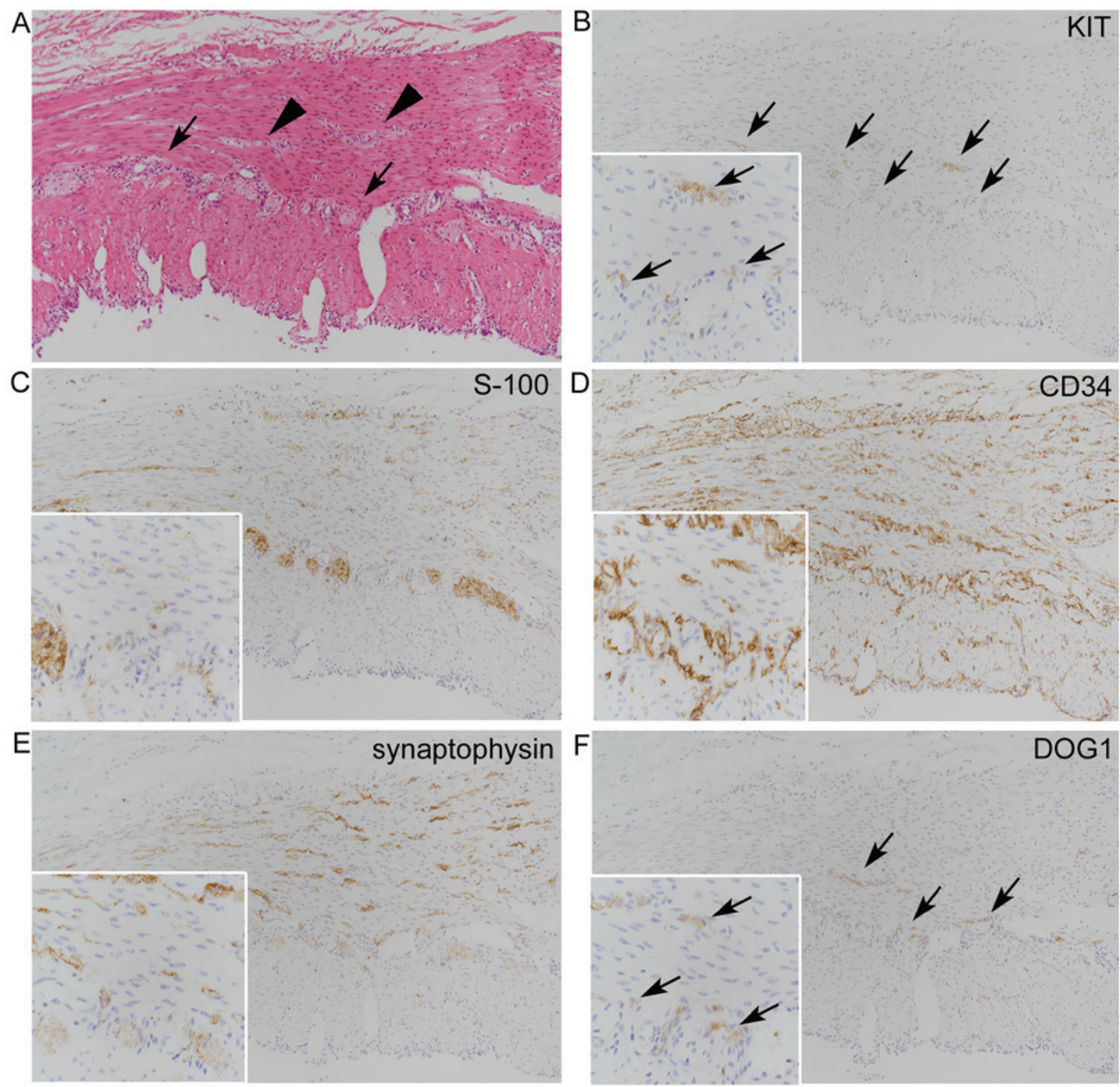

Figure 2. Hematoxylin and eosin staining and immunohistochemical analysis of a gastrointestinal tract-like muscular wall without mucosa in a teratoma (case 6). (A) Moderate-power view (magnification, x100) of hematoxylin and eosin staining demonstrating scattered neural tissues between two muscular layers (arrows) and within a muscular layer itself (arrowheads). The former resembles Auerbach's plexus. (B-F) Moderate-power views (magnification, x100) of immunostaining for (B) KIT, (C) S-100 protein, (D) CD34, (E) synaptophysin and (F) DOG1. Insets in (B-F) represent high-power views (magnification, x400) of positive cells in the same regions. (B) KIT ${ }^{+}$spindle and/or stellate cells (arrows) near the S-100 neural cells shown in (C) and corresponding to the DOG1 ${ }^{+}$ cells (arrows) shown in (F). (C) Distributions of intramuscular S-100+ cells similar to those of intramuscular (D) CD34 ${ }^{+}$cells and (E) synaptophysin ${ }^{+}$cells . CD, cluster of differentiation; DOG1, discovered on gastrointestinal stromal tumors 1.

accompanied by mucosae in 5 cases, MM-like structures in 5 cases, serosa-like features in 5 cases, and all of these components were present in 3 cases. Patients ranged in age from 19-52 years (mean, 34.3 years), and 4 patients had bilateral MCTs. The sizes of MCTs with these muscular walls ranged from 1.4-11.0 cm (mean, $4.8 \mathrm{~cm}$ ). The largest dimension of GI tract-like structures in each case ranged from $0.2-1.5 \mathrm{~cm}$ (mean, $0.6 \mathrm{~cm}$ ). GI tract-like muscular walls partially or totally demonstrated incomplete features, such as indistinct two-layered structures (all cases), thinning (7 cases) and adhesion to MM-like structures (1 case). In all muscular walls, neural tissues of varying size were observed between two conspicuous or inconspicuous muscular layers (Figs. 1 and 2), partially exhibiting Auerbach's plexus-like features, and also within the muscular layers (Fig. 2A). Gastric and intestinal mucosae were found in 2 and 4 cases, respectively. In 1 case, partially atrophic, gastric pyloric mucosa and small intestine-like mucosa were surrounded by mutual muscular walls (Fig. 1A). In another case, gastric body mucosa merged with marked flattened mucosa was observed. In 3 other cases, intestinal mucosae were difficult to distinctly divide into small and large intestinal types. Neoplastic lesions arising in GI tract-like structures, such as gastrointestinal stromal tumor (GIST), leiomyoma, glandular neoplasia and neuroendocrine tumor, were not observed.

Immunohistochemical features. Table II summarizes the immunohistochemical features of GI tract-like structures. 
Table II. Immunohistochemical features of gastrointestinal tract-like structures in ovarian MCTs.

\begin{tabular}{lccccccc}
\hline & & & \multicolumn{5}{c}{ Grading score $^{\mathrm{e}}$ of muscular walls } \\
\cline { 5 - 7 } Case & Keratin pattern of mucosa & $\begin{array}{c}\text { Diminished SMA } \\
\text { staining of muscular walls }\end{array}$ & $\mathrm{KIT}$ & $\mathrm{CD} 34$ & $\mathrm{~S}-100$ & Synaptophysin & DOG1 \\
\hline 1 & $\mathrm{~K} 7^{+} / \mathrm{K} 20^{-}>\mathrm{K} 7^{-} / \mathrm{K} 20^{+\mathrm{a}}$ & None & 1 & 1 & 1 & 0 & 0 \\
2 & - & Present & 2 & $-\mathrm{g}$ & 3 & $-\mathrm{g}$ & 0 \\
3 & $\mathrm{~K} 7^{+} / \mathrm{K} 20^{-}<<\mathrm{K} 7^{-} / \mathrm{K} 20^{+\mathrm{b}}$ & None & 1 & 3 & 2 & 2 & 0 \\
4 & $\mathrm{~K} 7^{+} / \mathrm{K} 20^{-}(\mathrm{G})^{\mathrm{c}}, \mathrm{K} 7^{-} / \mathrm{K} 20^{+}(\mathrm{I})^{\mathrm{c}}$ & Present & 1 & 3 & 2 & 2 & 0 \\
5 & - & None & 0 & 1 & 1 & 1 & 0 \\
6 & - & Present & 2 & 3 & 3 & 3 & 1 \\
7 & - & None & 1 & 3 & 3 & 3 & 0 \\
8 & $\mathrm{~K} 7^{+} / \mathrm{K} 20^{-}>>\mathrm{K} 7^{+} / \mathrm{K} 20^{+\mathrm{d}}$ & None & 1 & 2 & 2 & 1 & 0 \\
9 & $\mathrm{~K} 7^{-} / \mathrm{K} 20^{+}$only & None & 0 & 1 & 1 & 1 & 0 \\
\hline
\end{tabular}

${ }^{\mathrm{a}} \mathrm{K} 7^{+} / \mathrm{K} 20^{-}$cells and $\mathrm{K} 7^{-} / \mathrm{K} 20^{+}$cells were intermingled, but the former was slightly predominant; ${ }^{\mathrm{b}}$ majority of epithelial cells were $\mathrm{K} 7 / \mathrm{K} 20^{+}$, and $\mathrm{K} 7^{+} / \mathrm{K} 20^{-}$cells were focally present; ' ${ }^{g}$ gastric mucosa and intestinal mucosa were surrounded by the same muscular wall; ${ }^{\mathrm{d}}$ majority of epithelial cells were $\mathrm{K}^{+} / \mathrm{K} 20^{-}$cells, and $\mathrm{K} 7^{+} / \mathrm{K} 20^{+}$cells were focally present; ${ }^{e}$ positive spindle or stellate cells within muscular walls were graded as follows: 0 , no positive cells; $1,<1 \%$ positive muscular wall spindle or stellate cells; $2,1-5 \%$ positive muscular wall spindle or stellate cells; and 3,>5\% muscular wall spindle or stellate cells; ${ }^{\mathrm{f}}$ muscular walls represented muscularis propria and did not include muscularis mucosae; ${ }^{g}$ no immunoreactivity was observed in muscular walls or inner controls within the same MCTs. MCT, mature cystic teratoma; G, gastric mucosa; I, intestinal mucosa; K7, keratin 7; K20, keratin 20; SMA, $\alpha$-smooth muscle actin; CD, cluster of differentiation; DOG1, discovered on gastrointestinal stromal tumors 1 .

Table III. Relationship between MCT-related gastrointestinal tract-like muscular walls and clinicopathological variables.

Presence of MCT-related gastrointestinal tract-like muscular walls ${ }^{\mathrm{a}}$

\begin{tabular}{lccr}
\cline { 2 - 3 } Variable & Yes $(\mathrm{n}=9)$ & No $(\mathrm{n}=117)$ & P-value \\
\hline Age, years (mean) & $19-52(34.3)$ & $14-79(35.1)$ & 0.855 \\
Size of MCT containing muscular walls, cm (mean) & $1.5-11.0(4.8)$ & $1.0-21.0(4.0)(\mathrm{n}=135)^{\mathrm{b}}$ & 0.082 \\
Patients with bilateral MCTs, $\mathrm{n}$ & 4 & 19 & 0.096
\end{tabular}

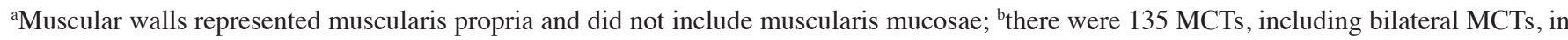
which tumor size was known. MCT, mature cystic teratoma.

In case 2, neither CD34 nor synaptophysin positivity was observed within muscular walls or the inner controls (vascular endothelium and neural cells, respectively). Hence, these findings were not included in the results. Muscular walls and MM-like structures were highlighted by SMA positivity, but the SMA positivity of the former was relatively weak in 3 cases (Fig. 1B). A few weakly $\mathrm{KIT}^{+}$spindle/stellate cells (not including $\mathrm{KIT}^{+}$mast cells) were observed chiefly nearby neural tissues between muscular layers in 7 cases (Figs. 1D and $2 \mathrm{~B}$ ), and were graded 1 and 2 in 5 cases and 2 cases, respectively. $\mathrm{S}-100^{+}$spindle or stellate cells were scattered within muscular layers and within the distinct neural tissues recognizable on H\&E-stained histology in all cases (Figs. 1E and $2 \mathrm{C}$ ). These intramuscular $\mathrm{S}-100^{+}$cells were considered to be richly distributed neural cells or networks, and were graded 1, 2 and 3 in 3 cases each. CD $34^{+}$spindle or stellate cells were scattered near the boundary zones of two muscular layers and within muscular layers in 8 cases (Figs. 1F and 2D) along with or without prominent $\mathrm{CD} 34^{+}$microvessels, and were graded 1, 2 and 3 in 3,1 and 4 cases, respectively. Other than in the context of distinct neural tissue positivity, intramuscular synaptophysin ${ }^{+}$spindle or stellate cells were observed in 7 cases (Fig. 2E) and were graded 1, 2 and 3 in 3,2 and 2 cases, respectively. The intramuscular distributions of $\mathrm{KIT}^{+}, \mathrm{CD} 4^{+}, \mathrm{S}-100^{+}$and synaptophysin ${ }^{+}$spindle or stellate cells were similar. A few DOG1 ${ }^{+}$spindle or stellate cells were observed near the Auerbach's plexus-like neural tissues in only 1 case (case 6; Fig. 2F), possibly corresponding with $\mathrm{KIT}^{+}$cells. Accompanying gastric mucosae contained only $\mathrm{K} 7^{+} / \mathrm{K} 20^{-}$cells in 1 case, and both $\mathrm{K}^{+} / \mathrm{K} 20^{-}$and $\mathrm{K} 7^{-} / \mathrm{K} 20^{+}$cells in 1 case. Intestinal mucosa specimens were composed of only $\mathrm{K} 7^{-} / \mathrm{K} 20^{+}$ cells in 2 cases, and were admixed with $\mathrm{K} 7^{+} / \mathrm{K} 20^{-}$cells and $\mathrm{K} 7-/ \mathrm{K} 20^{+}$cells in 2 cases. Serosa-like structures were positive for K7 (Fig. 1C). 
Table IV. Spearman's rank correlation analysis of immumohistochemical grading scores of mature cystic teratoma-related gastrointestinal tract-like muscular walls.

\begin{tabular}{|c|c|c|}
\hline Correlation of immunohistochemistry & P-value & rs \\
\hline KIT vs. CD34 $(n=8)^{a}$ & 0.130 & 0.58 \\
\hline KIT vs. S-100 protein & 0.014 & 0.78 \\
\hline KIT vs. synaptophysin $(n=8)^{a}$ & 0.753 & 0.12 \\
\hline KIT vs. DOG1 & 0.094 & 0.63 \\
\hline CD34 vs. $S-100$ protein $(n=8)^{a}$ & 0.003 & 0.89 \\
\hline CD34 vs. synaptophysin $(n=8)^{a}$ & 0.009 & 0.84 \\
\hline CD34 vs. DOG1 $(n=8)^{a}$ & 0.426 & 0.33 \\
\hline S-100 protein vs. synaptophysin $(n=8)^{a}$ & 0.002 & 0.91 \\
\hline S-100 protein vs. DOG1 & 0.129 & 0.54 \\
\hline Synaptophysin vs. DOG1 $(\mathrm{n}=8)^{\mathrm{a}}$ & 0.184 & 0.52 \\
\hline
\end{tabular}

Muscular walls represented muscularis propria and did not include muscularis mucosae. ${ }^{a}$ Excluding 1 case (case 2) in which CD34 and synaptophysin were not positive in the internal controls of the mature cystic teratomas. CD, cluster of differentiation; DOG1, discovered on gastrointestinal stromal tumors 1 .

Association between various histopathological and immunohistochemical features. The presence of GI tract-like muscular walls was not statistically associated with age $(\mathrm{P}=0.855)$, MCT size $(\mathrm{P}=0.082)$ or bilateral presence of MCTs $(\mathrm{P}=0.096$; Table III). Spearman's rank correlation analysis demonstrated significant correlations between grading scores of $\mathrm{KIT}^{+}$and $\mathrm{S}-100^{+}$cells $(\mathrm{P}=0.014), \mathrm{CD}^{+}$ and $\mathrm{S}-100^{+}$cells $(\mathrm{P}=0.003), \mathrm{CD}^{+} 4^{+}$and synaptophysin ${ }^{+}$cells $(\mathrm{P}=0.009)$ and $\mathrm{S}-100^{+}$and synaptophysin ${ }^{+}$cells $(\mathrm{P}=0.002)$; however, no significant correlations were observed between other combinations (Table IV). Fisher's exact test (data not shown) revealed significant relationships between $\mathrm{CD} 34^{+}$ and $\mathrm{S}-100^{+}$cells $(\mathrm{P}=0.018)$ and between $\mathrm{S}-100^{+}$and synaptophysin $^{+}$cells $(\mathrm{P}=0.048)$; however, it revealed no significant associations between $\mathrm{KIT}^{+}$and $\mathrm{S}-100^{+}$cells $(\mathrm{P}=0.500)$ or between $\mathrm{CD} 4^{+}$and synaptophysin ${ }^{+}$cells $(\mathrm{P}=0.143)$. No statistical associations were observed between decreased SMA positivity of muscular walls and other immunostaining results.

\section{Discussion}

In the present study, GI tract-like muscular walls with or without other components were observed in $7.1 \%$ of MCT cases. This incidence is consistent with the occurrence of GI-type epithelium with or without other components in MCTs, which has been reported to be $7-13 \%(6,13)$. Totally organized GI tracts within ovarian MCTs are rare, with $<20$ previously reported cases (8-12). The present study revealed GI tract-like structures containing mucosa, MM, muscular walls and serosa in $3(2.4 \%)$ of $126 \mathrm{MCT}$ cases, and muscular walls without mucosa in $4(3.2 \%)$ cases.

The detected MCT-related GI tract-like structures were relatively small and histologically differed somewhat from those of actual GI tracts. Accompanying intestinal epithelia were frequently difficult to distinguish as small vs. large intestine, and gastric mucosae were partially atrophic or prominently flattened. Muscular walls commonly demonstrated inconspicuous two-layered structures, thinning and partially diminished SMA positivity. These findings underscore the disorganization of the GI tracts, which may influence the development of ICCs. However, a high percentage (78\%) of the present cases had $\mathrm{KIT}^{+}$spindle or stellate cells chiefly nearby the neural tissues between muscular layers, which is consistent with those of ICCs of actual GI tracts (14). KIT and S-100 grading scores were also significantly correlated with each other. Although DOG1 is also known to be a marker of ICCs $(15,16)$, DOG1 co-expression in $\mathrm{KIT}^{+}$ICCs was observed in only 1 case.

A study by Agaimy et al (11) first described KIT ${ }^{+}$ICCs within GI tract-like muscular derivatives in 2 MCTs, and a case of hyperplastic ICCs was reported later (12). In the present study, an increased number of $\mathrm{KIT}^{+}$cells were not observed; however, there appeared to be more intramuscular $\mathrm{CD} 34^{+}$spindle or stellate cells compared to $\mathrm{KIT}^{+}$cells. As CD34 is also a marker of ICCs (14), these findings suggest the possibility of ICC hyperplasia. However, $\mathrm{CD} 34^{+}$cells are also detectable in normal endoneural fibroblasts (14) and in peripheral nerve sheath tumors (17). Furthermore, in the present study, the distribution of intramuscular $\mathrm{CD} 34^{+}$cells resembled that of intramuscular S-100 ${ }^{+}$neural cells, and their grading scores were closely correlated with each other. Therefore, $\mathrm{CD} 4^{+}$cells are expected to be neuron-related cells rather than ICCs. Similarly, intramuscular synaptophysin ${ }^{+}$cells are expected to represent intramuscular neural cells rather than neuroendocrine cells because synaptophysin positivity may be found in synaptic vesicles of neural cells (18) and the neuroendocrine system of GI tracts is usually present in the mucosa and submucosa, and is unknown within the muscularis propria (14). We believe that ICC hyperplasia is a rare event in MCT-related GI tract-like structures.

GISTs are considered to arise from ICCs or their precursor cells $(3,17,19)$; however, they were previously misinterpreted as smooth muscle tumors in the 'pre-KIT era' (12). Our previous review of the literature identified a case report describing a 'spindle cell nodule' in a MCT-related gastric wall (7). However, based on the description and the photomicrographs in this article (7), this spindle cell nodule did not demonstrate a well-demarcated GIST-like configuration, thus was likely a reactive stromal reaction associated with an ulcer. Therefore, to the best of our knowledge, no distinct cases of GISTs arising in MCTs have been reported previously, regardless of their incidence in normal GI tract tissue $(3,15,17,19)$ and the presently demonstrated frequent $\mathrm{KIT}^{+}$ICCs within MCT-related GI tract-like structures. Agaimy et al (11) reported that no previous cases of MCT-related GISTs have contributed to unknown underlying pathogenic factors other than the rarity of somatic secondary tumors in MCTs. Based on the present results, this may be partially due to the rarity of ICC hyperplasia.

In conclusion, the present study revealed GI tract-like muscular walls in $7.1 \%$ of ovarian MCT cases, which frequently contained $\mathrm{KIT}^{+}$ICCs but did not demonstrate any hyperplastic features. The present study included a limited number of cases. Therefore, to elucidate true incidence of $\mathrm{KIT}^{+} \mathrm{ICC}$ in MCT, further study using a larger number of cases is required. 


\section{References}

1. Scully RE, Young RH and Clement PB: Tumors of the ovary, maldeveloped gonads, fallopian tube and broad ligament. In Atlas of Tumor Pathology. 3rd edition. fascicle 23. Rosai J and Sobin LH (eds). American Registry of Pathology, Washington, 1998.

2. Russel P and Bannatyne P (eds): Surgical Pathology of the Ovaries. Churchill Livingstone, New York, NY, pp416-452, 1989.

3. Rosai J (ed): Rosai and Ackerman's Surgical Pathology. 10th edition. Mosby/Elsevier, Philadelphia, PA, 2011.

4. Kurman RJ, Carcangiu ML and Herrington CS, Young RH (eds): WHO Classification of Tumours of Female Reproductive Organs. 4th edition. IARC Press, Lyon, pp60-61, 2014.

5. Gundersen JH and Greene RR: Vermiform appendix in benign cystic teratoid tumor of the ovary. Am J Obstet Gynecol 89: 534-535, 1964.

6. Woodfield B, Kats DA, Cantrell CJ and Bogard PJ: A benign cystic teratoma with gastrointestinal tract development. Am J Clin Pathol 83: 236-240, 1985.

7. Sahin AA, Ro JY, Chen J and Ayala AG: Spindle cell nodule and peptic ulcer arising in a fully developed gastric wall in a mature cystic teratoma. Arch Pathol Lab Med 114: 529-531, 1990.

8. Fujiwara K, Ginzan S and Silverberg SG: Mature cystic teratomas of the ovary with intestinal wall structures harboring intestinal-type epithelial neoplasms. Gynecol Oncol 56: 97-101, 1995.

9. Tang P, Soukkary S and Kahn E: Mature cystic teratoma of the ovary associated with complete colonic wall and mucinous cystadenoma. Ann Clin Lab Sci 33: 465-470, 2003.

10. Ki EY, Jang DG, Jeong DJ, Kim CJ and Lee SJ: Rare case of complete colon structure in a mature cystic teratoma of the ovary in menopausal woman: A case report. BMC Women's Health 16 70, 2016.
11. Agaimy A, Lindner M and Wuensch PH: Interstitial cells of Cajal (ICC) in mature cystic teratoma of the ovary. Histopathology 48: 208-209, 2006

12. Agaimy A and Wünsch PH: Coexistence of interstitial cell of Cajal hyperplasia and microcarcinoidosis in a mature cystic teratoma. Histopathology 52: 260-262, 2008.

13. Blackwell WJ, Dockerty MB, Masson JC and Mussey RD: Dermoid cysts of the ovary: Their clinical and pathologic significance. Am J Obstet Gynecol 51: 151-172, 1946.

14. Mills SE (ed): Histology for pathologists. 4th edition. Lippincott Williams \& Wilkins, Philadelphia PA, pp605-708, pp1255-1276, 2012.

15. Espinosa I, Lee CH, Kim MK, Rouse BT, Subramanian S, Montgomery K, Varma S, Corless CL, Heinrich MC, Smith KS, et al: A novel monoclonal antibody against DOG1 is a sensitive and specific marker for gastrointestinal tumors. Am J Surg Pathol 32: 210-218, 2008.

16. Miettinen M, Wang ZF and Lasota J: DOG1 antibody in the differential diagnosis of gastrointestinal stromal tumors. A study of 1840 cases. Am J Surg Pathol 33: 1401-1408, 2009.

17. Fletcher CDM, Bridge JA and Hogendoorn PCW, Mertens F (eds): WHO Classification of Tumours of Soft tissues and Bone. 4th edition. IARC Press, Lyon, pp170-186, 2013.

18. Dabbs (ed): Diagnostic immunohistochemistry. 2nd edition. Churchill Livingston/Elsevier, Philadelphia, PA, pp263, 2006.

19. Hirota $\mathrm{S}$ and Isozaki K: Pathology of gastrointestinal stromal tumors. Pathol Int 56: 1-9, 2006. 